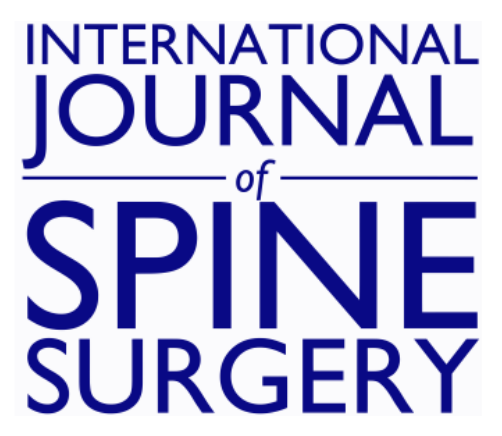

\title{
Dome Laminotomies at Adjacent Segments in Cervical Laminoplasty
}

Jeffrey H. Zimering and Konstantinos Margetis

Int J Spine Surg published online 17 September 2021

http://ijssurgery.com/content/early/2021/09/14/8112

This information is current as of April 26, 2023.

Email Alerts Receive free email-alerts when new articles cite this article. Sign up at:

http://ijssurgery.com/alerts

The International Journal of Spine Surgery

2397 Waterbury Circle, Suite 1,

Aurora, IL 60504, Phone: +1-630-375-1432 


\title{
Dome Laminotomies at Adjacent Segments in Cervical Laminoplasty
}

\author{
JEFFREY H. ZIMERING, MD, KONSTANTINOS MARGETIS MD, PhD \\ Department of Neurosurgery, Mount Sinai Health System, New York, New York
}

\begin{abstract}
Background: Cervical laminoplasty is an established and effective surgical treatment for neurologic dysfunction associated with cervical myelopathy. "Dome laminotomies" involve undercutting the laminae adjacent to the laminoplasty levels to decompress and prevent spinal cord kinking on the lamina edges. The technique allows for a decrease in the number of instrumented laminae, smaller surgical exposure, and preservation of muscular attachments at the top of $\mathrm{C} 2$ and $\mathrm{C} 7$. We investigated whether dome laminotomies are associated with satisfactory neurologic and pain outcome.

Methods: This study involved a retrospective review of consecutive patients treated at a single institution between November 2015 and September 2018. The patients underwent a C3-C6 laminoplasty with dome laminotomies of the caudal edge of $\mathrm{C} 2$ and the cranial edge of $\mathrm{C} 7$ lamina. Postoperative evaluations of pain, myelopathy symptoms, and complications occurred at early (mean, $\sim 2$ months) and late (mean, $\sim 15$ months) time points.

Results: Twenty-one patients were enrolled (mean age, 62 years). Mean axial pain score improved significantly at both the early $(P=.02)$ and late $(P=.045)$ postoperative evaluations compared with the mean baseline pain score. A total of $92 \%$ of patients experienced resolution of baseline hand dysfunction at the early postoperative follow-up, and $84 \%$ maintained it at the late follow-up. Two-thirds of patients experienced (late) significant improvement $(P<0.05)$ in baseline balance impairment. Postoperative response rates for urinary dysfunction were $58 \%$ (early) and $42 \%$ (late). There were no wound complications, late neurologic deterioration, kyphosis, or C5 palsy.

Conclusions: C3-C6 laminoplasty with $\mathrm{C} 2$ and $\mathrm{C} 7$ dome laminotomies was safe, well tolerated, and associated with satisfactory early and late improved neurologic function and decreased pain.
\end{abstract}

Cervical Spine

Keywords: dome laminotomy, cervical laminoplasty, pain

\section{INTRODUCTION}

Cervical spondylotic myelopathy causes decreased hand dexterity, urinary dysfunction, and/ or gait instability. ${ }^{1}$ Cervical laminoplasty is a common neurosurgical technique for the treatment of cervical stenosis causing cervical spondylotic myelopathy. ${ }^{2}$ Limiting the laminoplasty levels by not including the $\mathrm{C} 2$ and $\mathrm{C} 7$ shortens the operative time, decreases operative exposure, and preserves important muscle attachments. ${ }^{3}$ It has been described to undercut the $\mathrm{C} 2$ and $\mathrm{C} 7$ laminae to limit the laminoplasty levels and avoid inadequate decompression. ${ }^{4,5}$ The purpose of the dome laminectomy is to directly decompress and prevent static or dynamic kinking of the spinal cord after its expected, postdecompression dorsal migration (Figure 1). We undertook to evaluate whether the technique of performing dome laminotomies at adjacent segments is associated with satisfactory neurologic outcomes and decreased postoperative pain.

\section{METHODS}

\section{Patients}

The study examined consecutive patients who underwent a C3-C6 laminoplasty with dome laminotomies at C2 and C7. Dome laminotomy is defined as the undercutting (bilateral laminotomies, more extensive on the ventral aspect of the laminae) of the caudal (or "trailing") edge of $\mathrm{C} 2$, or the cranial (or "leading") edge of C7 laminae. The patients were operated on by the senior author at a single institution between November 2015 and September 2018. The study was approved by the institution's Investigational Review Board, and waiver of the consent process was obtained.

\section{Copyright 2021 by International Society for the Advancement of Spine Surgery.}



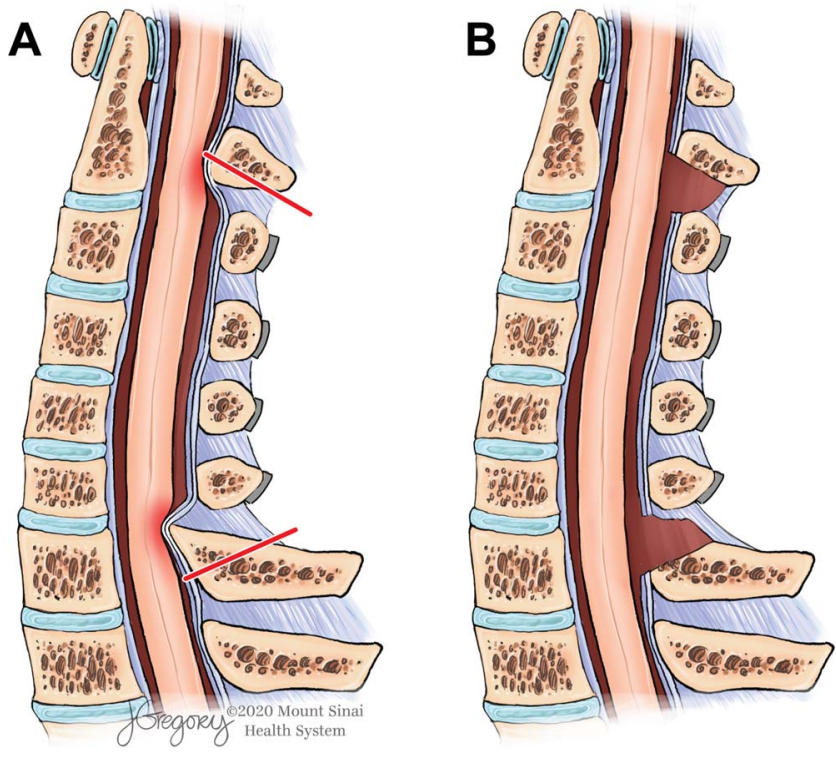

Figure 1. (A) A sagittal, midline view of the cervical spine following a C3-C6 laminoplasty without dome laminotomies. The dorsal migration of the spinal cord following the decompressive effect of the laminoplasty at the C3-C6 levels leads to kinking and compression (red-shaded areas) of the spinal cord by the caudal edge of the C2 lamina and the cranial edge of the C7 lamina. The kinking can be static and/or dynamic. Adding C2 and C7 laminotomies, defined by the red lines, leads to an improved decompression, which is depicted in panel B. (B) The additional decompression afforded by the dome laminotomies prevents any spinal cord kinking. Illustration by Jill K. Gregory, used with permission of cMount Sinai Health System.

\section{Indications for Surgery}

The indications for surgery were cervical myelopathy with/without radiculopathy due to cervical stenosis or mild forms of ossification of posterior longitudinal ligament that respected the K-line rule. ${ }^{6}$ The presence of baseline cervical kyphosis $>13^{\circ}$ on standing lateral X-ray, spondylolisthesis between $\mathrm{C} 2$ and $\mathrm{C} 7$ (defined as $>2 \mathrm{~mm}$ of anterolisthesis) on neutral lateral X-ray, or the presence of cervical instability in any cervical level was a contraindication. The instability was defined as dynamic sagittal plane translation of more than $3.5 \mathrm{~mm}$, or sagittal plane rotation of more than $20^{\circ}$ on flexion-extension X-rays. ${ }^{7}$ The presence of severe pain (more than numeric rating scale $8 / 10$ ) was a contraindication, unless this was felt to be related to upper cervical radiculopathy, which can be addressed with foraminotomies.

\section{Parameters}

The main outcome measures were neck pain (numeric rating scale) and neurologic outcome. The neurologic outcome was assessed qualitatively by patient-reported changes in the severity of functional impairment domains of cervical myelopathy: hand dexterity/balance/urinary dysfunction. Hand dysfunction and balance impairment (including gait instability) were graded by patient subjective report only, and they were characterized as absent, stable, improved, or worsened at the measured study time points. Urinary dysfunction included urinary symptoms associated with neurogenic bladder, and in women, urinary frequency that did not require catheterization. The secondary outcomes were surgery-related complications and the development of cervical deformity or instability on postoperative imaging. The data were collected retrospectively. Descriptive statistics were used and comparisons were made using unpaired Student $t$-test and Fisher exact test and a prespecified cutoff level for significance of $P<.05$.

\section{Surgical Technique}

The operative technique is standardized as follows. Standard endotracheal intubation and induction of general anesthesia was performed while maintaining spinal precautions. Baseline motor evoked potentials, somatosensory evoked potentials, and electromyography recordings were obtained. Gardner-Wells tongs were applied. The patient was positioned prone on the Jackson table with a foamy face mask under the face, which was supported on a rigid, radiolucent head frame. Neuromonitoring was repeated after flipping the patient, and then after applying $10 \mathrm{lb}$ of traction. A lateral X-ray was obtained for incision localization. We exposed the spinous process and lamina of $\mathrm{C} 3$ down to C6 as well as the caudal edge of the $\mathrm{C} 2$ spinous process and lamina, and the cranial edge of the $\mathrm{C} 7$ spinous process and lamina. The exposure was extended laterally to the junction of the lamina and lateral mass on the "hinge" side of the laminoplasty. On the opening side of the laminoplasty, the exposure was extended to the lateral one third of the lateral masses while preserving the facet capsules. The opening trough was done on the side that was more symptomatic, given that a more extensive decompression of the spinal canal was achieved on the side of the opening trough. In cases in which the symptoms were equal in severity on both sides, we selected the dominant hand side for the opening trough. A 3-mm matchstick drill bit was then used to drill the cranial edge of the C7 lamina and base of the $\mathrm{C} 7$ spinous process. We then drilled a full-thickness trough at the junction of the lamina and lateral mass on the opening trough side. 
Foraminotomies were performed at this phase if they were indicated. We then drilled on the caudal edge of the C2 lamina and base of the $\mathrm{C} 2$ spinous process. We then performed a partial-thickness trough at the junction of the laminae and lateral masses on the hinge side. A small upgoing curette was used to release the ligamentum flavum connecting the undersurface of the laminae to the lateral masses on the open trough side.

We gently uplifted the C6 lamina by taking advantage of the elastic properties of the bone. Special caution was taken to avoid fracturing the lamina at the hinge trough area. We then inserted an 8-mm laminoplasty plate, which was secured with 2 miniscrews, $5 \mathrm{~mm}$ in length, on the lamina and same number/size of screws on the lateral mass. The same process was repeated for $\mathrm{C} 5, \mathrm{C} 4$, and C3. Kerrison rongeurs were used to resect the ligamentum flavum at the $\mathrm{C} 2-\mathrm{C} 3$ and $\mathrm{C} 6-\mathrm{C} 7$ levels. The adequacy of this resection was confirmed by inspection and palpation of the dorsal epidural space with a Woodson elevator. Standard wound irrigation and hemostasis was performed. Then, we placed 2 medium subfascial Hemovac drains. The muscle, fascia, and deep subcutaneous layers were reapproximated and closed with Vicryl-0s. The dermis was closed with Vicryl 2-0s, and a Monocryl 3-0 was run in a subcuticular fashion. Figure 2 shows the bony anatomy at the completion of the operation.

\section{RESULTS}

\section{Baseline Clinical Characteristics}

A total of 21 consecutive patients (15 men and 6 women) having a mean \pm SD age of $62.2 \pm 10.4$ years met the criteria for inclusion. Early and longer-term ("late") postoperative follow-up clinical evaluation(s) occurred at a mean $\pm \mathrm{SD}$ of $2.0 \pm 1.5$ months and $14.9 \pm 13.1$ months, respectively. The baseline clinical characteristics of the study patients are shown in Table 1. All patients had CSM; 2 of them also had radiographic evidence for mild OPLL.

\section{Axial Pain}

A total of 10 of 21 patients (48\%) in our study group reported baseline neck pain preoperatively, including 7 of $21(33 \%)$ having mild, 2 of $21(4.7 \%)$ having moderate, and 1 of $21(9.5 \%)$ having severe pain (Figure 3). In the early postoperative period, 11 of 21 patients $(52 \%)$ had no axial neck pain and that

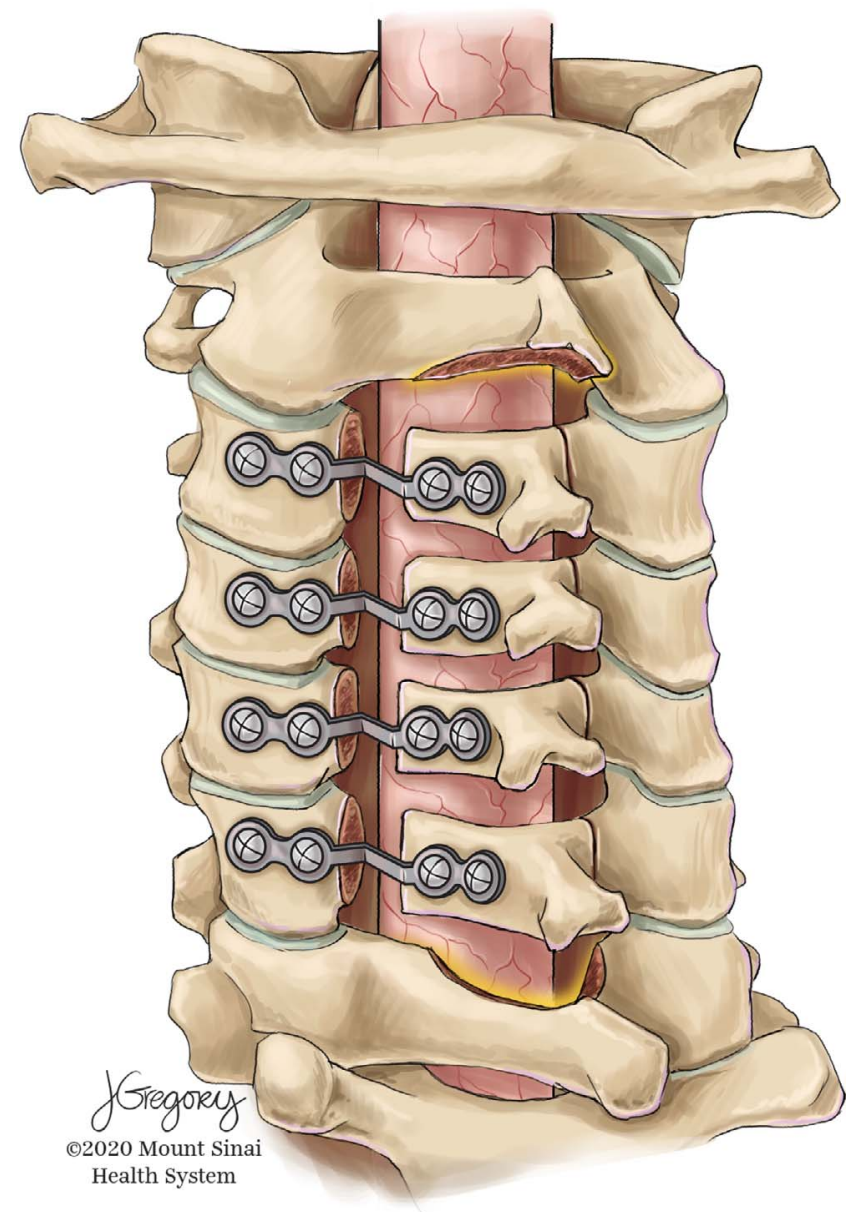

Figure 2. A dorsolateral view of the osseous structures at the completion of C3-C6 laminoplasty and C2/C7 dome laminotomies. Illustration by Jill K. Gregory, used with permission of (CMount Sinai Health System.

is unchanged compared with the baseline percentage of patients with no pain (Figure 3). The proportion of patients reporting mild pain increased slightly to 9 of $21(43 \%)$ from 7 of $21(33 \%)$ preoperatively. This was because of 1 patient whose severe preoperative pain decreased significantly and 1 patient (pain-free at baseline) who experienced the new onset of mild postoperative pain. Only 1 patient reported moderately severe axial neck pain preoperatively; the pain had resolved in the early postoperative period, and it had not recurred by

Table 1. Baseline clinical characteristics in the study patients.

\begin{tabular}{lc}
\hline Parameter & Value \\
\hline Demographics & \\
Age, mean \pm SD, y & $62.2 \pm 10.3$ \\
Sex & $15 \mathrm{M}, 6 \mathrm{~F}$ \\
Diagnosis & 21 \\
CSM, No. & 2 \\
Mild OPLL, No. &
\end{tabular}

CSM, cervical spondylotic myelopathy; OPLL, ossification posterior longitudinal ligament. 


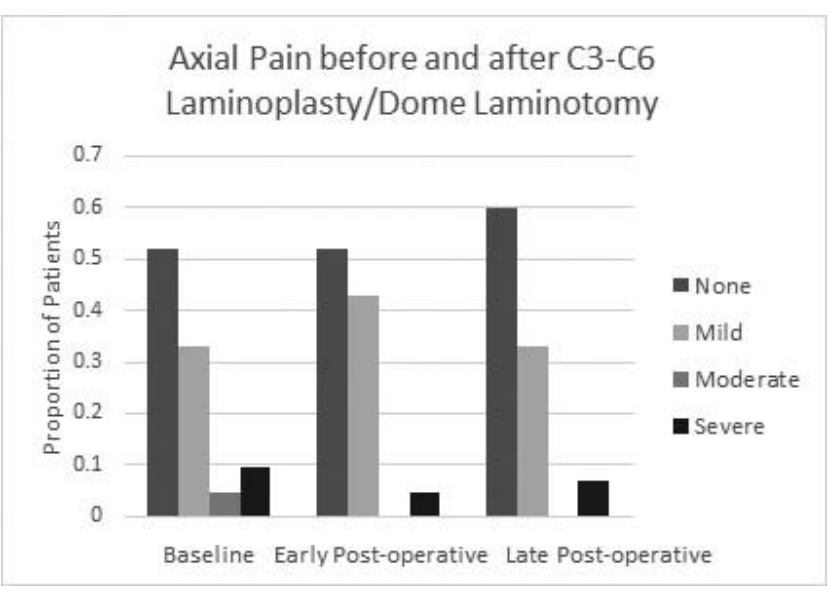

Figure 3. Axial pain before and after C3-C6 laminoplasty with dome laminotomy. Results are proportions of patients with no, mild, moderate, or severe pain. Baseline and early postoperative visit $(n=21)$ : mean, 2.9 months; late postoperative visit $(n=16)$ : mean, 14.9 months.

15 months postoperatively (Figure 3 ). In 2 patients with severe preoperative axial pain, pain substantially improved in 1 patient and persisted early and at the 15-month visit in the second patient (Figure $3)$. There was no significant difference in the categories of no pain, mild, moderate, or severe pain during the postoperative follow-up period (Table 2). We next compared mean pain scores in patients evaluated at the baseline, early, and late postoperative periods. Patient self-reports of pain severity ranged from 1 to 5 (mild), 6 to 7 (moderate), and 8 to 10 (severe). Mean axial neck pain score improved significantly at both the early $(P=.02)$ and late $(P=.045)$ postoperative evaluations compared with mean baseline pain score (Figure 4).

\section{Neurologic Function}

Baseline hand dysfunction improved significantly at the early and later postoperative time periods. The early response rate, (ie, proportion of patients who improved) was $92 \%(P=.0001)$ and the late response rate was $84 \%(P=.001$; Figure 5$)$. Balance impairment improved significantly at the late postoperative evaluation $(67 \%$ response rate, $P=$

Table 2. Change in axial neck pain severity around the time of cervical laminoplasty. ${ }^{\text {a }}$

\begin{tabular}{lccc}
\hline Pain Severity & Baseline & Early Postoperative & Late Postoperative \\
\hline None & $11 / 21$ & $11 / 21$ & $10 / 16$ \\
Mild & $7 / 21$ & $9 / 21$ & $5 / 16$ \\
Moderate & $1 / 21$ & $0 / 21$ & $0 / 16$ \\
Severe & $2 / 21$ & $1 / 21$ & $1 / 16$
\end{tabular}

${ }^{\mathrm{a}}$ Results are proportion of patients. Five patients were lost to long-term followup.

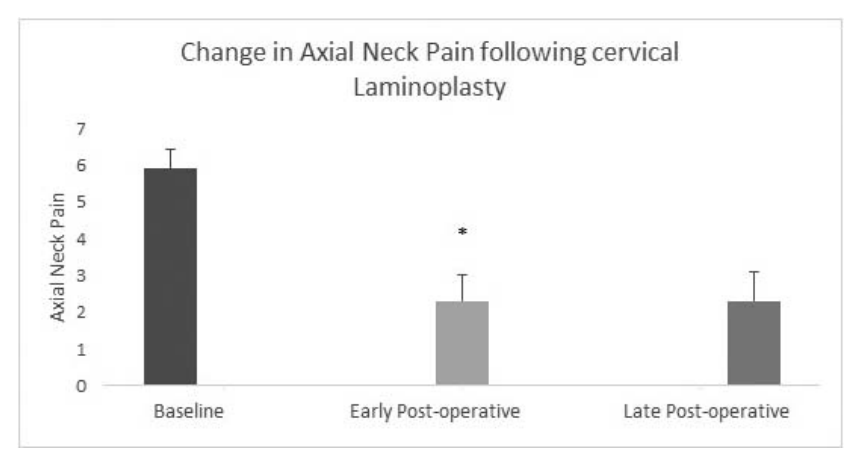

Figure 4. Change in mean axial pain score at early and late postoperative time points. There was a significant reduction in the mean pain score at both the early and late postoperative examinations compared with mean baseline pain score. ${ }^{\star} P<.05$ compared to baseline mean axial pain.

.04 ), and there was a trend of improvement in balance function at the early postoperative time point $(57 \%$ response rate, $P=.06$; Figure 5). Urinary dysfunction improved at the early $(58 \%$ response rate) and late ( $42 \%$ response rate) postoperative evaluations; however, the results did not reach a statistically significant level, possibly because of the small numbers of affected patients (Figure 5). Only 5 of 21 patients $(24 \%$; 3 women and 2 men) experienced urinary dysfunction preoperatively. All 3 women experienced postoperative improvement in urinary symptoms, but 2 men continued to experience neurogenic bladder symptoms postoperatively, that is, a total 3 of 21 patients $(14 \%)$ improved. The "urinary dysfunction response rate" represents the proportion of patients who improved postoperatively divided by the proportion of preoperatively affected patients, or $14 \% / 24 \%=$ $58 \%$.

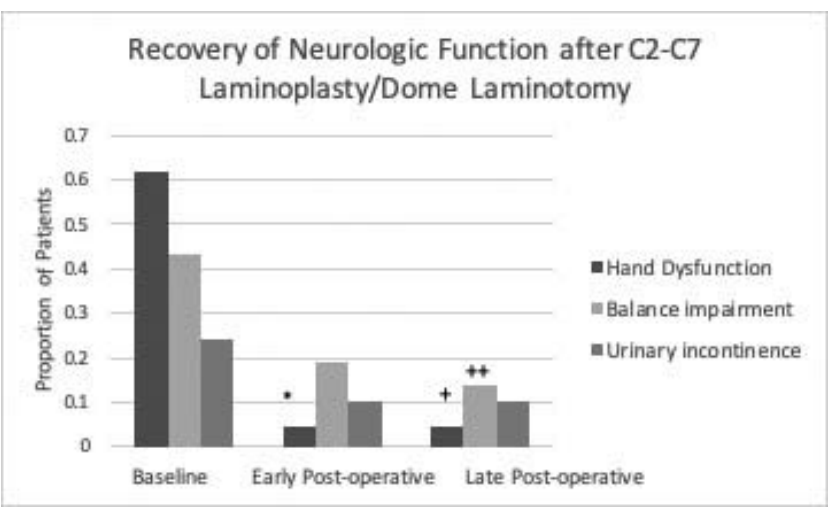

Figure 5. Recovery of neurologic function following C3-C6 laminoplasty with dome laminotomy. There was a significant improvement in hand function at the early and late examinations, and balance impairment improved significantly at the late examination. ${ }^{\star} P=.0001 ;+P=.001 ;++P<.05$ compared to baseline proportion. 


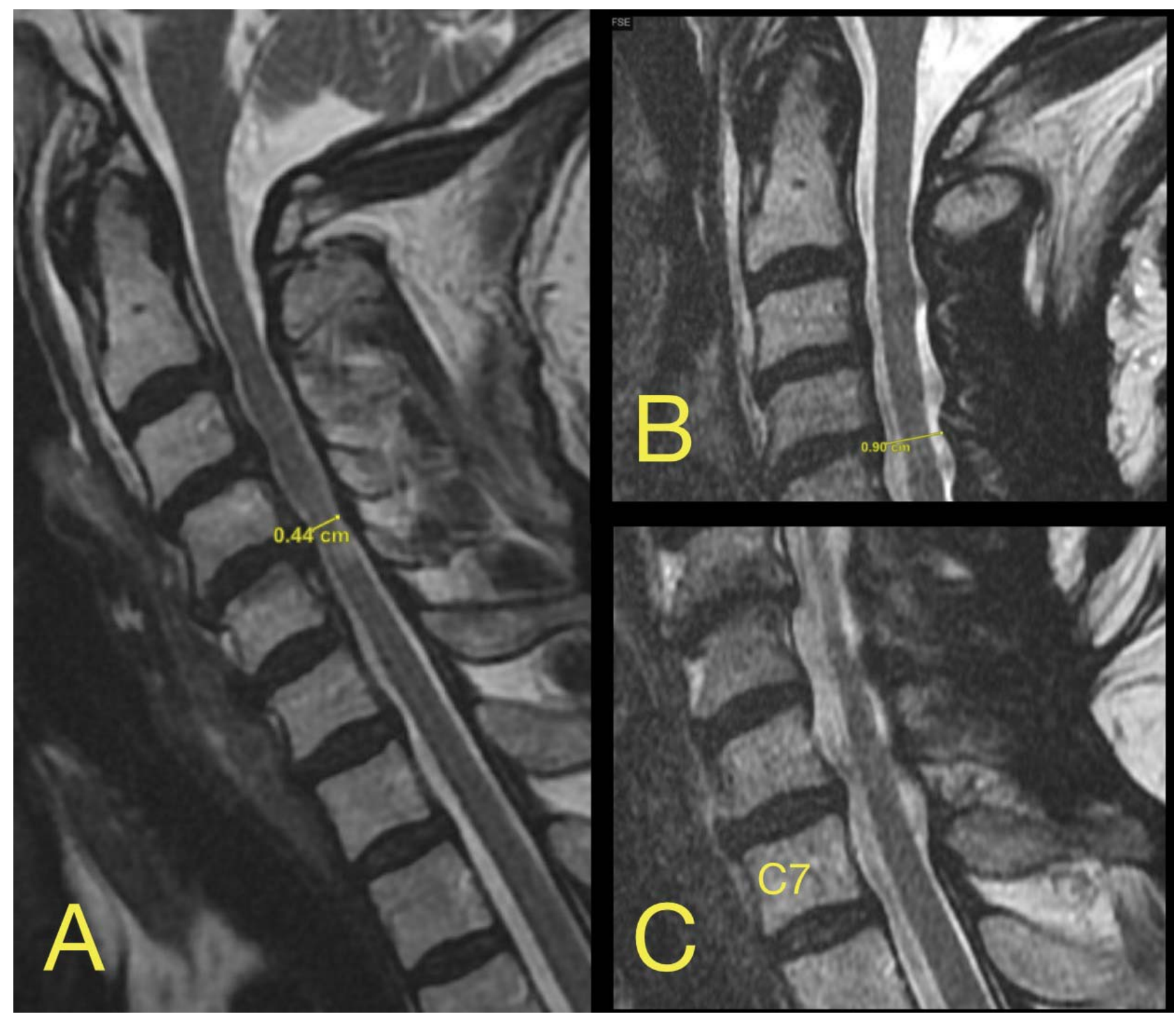

Figure 6. (A) Preoperative sagittal T2 magnetic resonance image which revealed degenerative, superimposed on congenital stenosis with anterior-posterior diameter as low as $4.4 \mathrm{~mm}$. (B) Decompressed C2-C3 level. (C) Decompressed C6-C7 level.

\section{Complications}

There was no occurrence of wound complication, C5 palsy, or late neurologic deterioration. In 1 patient, there was a new, stable 3-mm anterolisthesis $\mathrm{C} 7$ on $\mathrm{T} 1$ on postoperative radiographic evaluation which was not associated with any symptoms.

\section{DISCUSSION}

The study provides information about the efficacy and safety profile of our nuanced laminoplasty technique. As a retrospective study, there is no inherent control group for direct comparison. However, our profile appears satisfactory, and the study results allow for an indirect comparison with other variations of the technique from the published literature.

New postoperative axial pain ( 1 of $21 ; 4.8 \%$ ) was an uncommon occurrence in our study, in close agreement with the results of Hosono et $\mathrm{al}^{8}$ following C3-C6 laminoplasty without dome laminotomies. The similar pain outcome between the 2 studies suggests that addition of dome laminotomy at $\mathrm{C} 2$ and $\mathrm{C} 7$ does not alter the favorable pain outcome of C3-C6 laminoplasty (Figure 6). Riew et $\mathrm{al}^{3}$ conducted a systematic review and found evidence that $\mathrm{C} 2$ procedures that spare the semispinalis cervicis muscle were associated with a lower incidence of postoperative axial pain. In the present study, the addition of $\mathrm{C} 2$ dome laminotomy adhered 


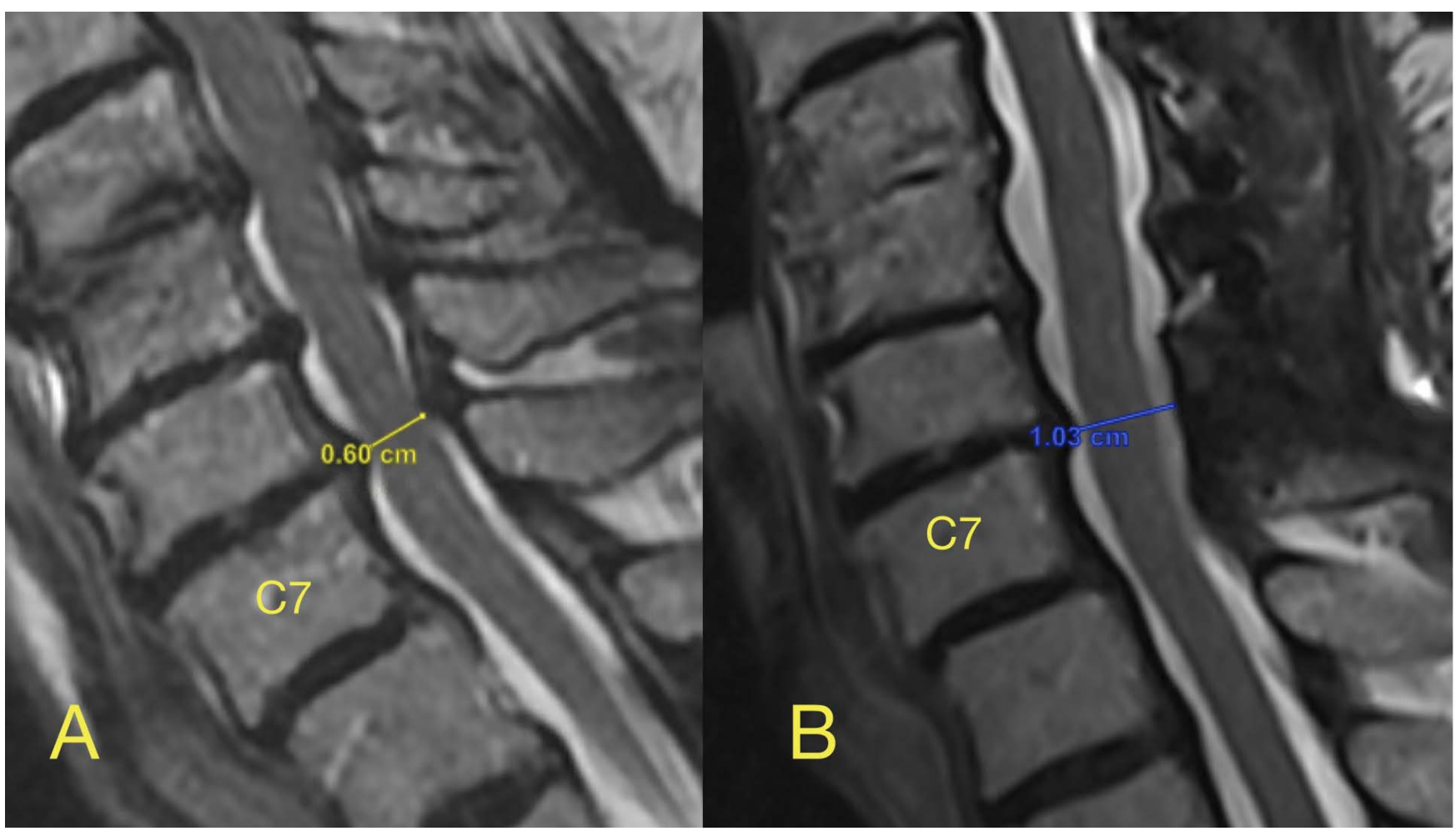

Figure 7. (A) Preoperative stenosis at the C6-C7 level with an AP diameter of the spinal canal of only $6 \mathrm{~mm}$. (B) Image was obtained after a fall experienced 10 months after surgery which was associated with subjective weakness. It shows an increase in AP diameter of the spinal canal to 10.3 mm with adequate decompression of the spinal cord at the C6-C7 level. Of note, the patient had a stable mild spondylolisthesis at C7-T1 that remained unaltered postoperatively.

to the principle of preserving the $\mathrm{C} 2$ muscle insertion.

In the current study, zero patients experienced C5 palsy, which compares favorably with prior reports reporting an incidence of postoperative C5 palsy of $8 \%$ following C3-C6 laminoplasty without dome laminotomy. ${ }^{3}$ Faster operative time and shorter wound length of $\mathrm{C} 3-\mathrm{C} 6$ (vs $\mathrm{C} 3-\mathrm{C} 7$ ) laminoplasty have been cited $^{8}$ as likely contributing to low incidence of wound complications.

The prevalence of urinary dysfunction in our study $(24 \%)$ was not substantially higher than the prevalence of clinically relevant urinary symptoms $(18 \%)$ previously reported among men and women patients (mean age, 58 years) undergoing elective cervical spine surgery. ${ }^{11}$ Myelopathy (vs no myelopathy) was previously associated with a nearly 3fold higher rate of baseline clinical urinary dysfunction ( $30 \%$ vs $11 \%$ ) in the same study of cervical spine surgery patients reported by Lieberman et al. ${ }^{11}$ It is possible that postoperative improvement in urinary symptoms experienced by some patients may have been due in part to relief of spinal cord compression. Still, urinary dysfunction among women is quite common, ${ }^{12}$ and its underlying etiology may be multifactorial.
Another advantage of dome laminotomy is the prevention of impingement of the cord by the cranial edge of C7 lamina due to dorsal expansion of the dura in the decompressed area. This impingement has been described by Hosono et $\mathrm{al}^{8}$ in the $\mathrm{C} 3 / \mathrm{C} 6$ laminoplasty approach, where they did not perform $\mathrm{C} 7$ dome laminotomy. Although late neurologic deterioration was not observed in any of our patients, Sakuara et $\mathrm{al}^{9}$ reported late neurologic deterioration at the caudal segment in 3 of 137 patients $(2.2 \%)$ 16-60 months after C3-C6 laminoplasty. Longer-term follow-up in a larger group of patients may be required to exclude the possibility of late neurologic deterioration following C3-C6 laminoplasty with C7 dome laminotomy. The expected risk is minimized by virtue of the $\mathrm{C} 7$ dome laminotomy's increase in the anterior-posterior diameter of the spinal canal at the cranial aspect of C7 lamina (Figure 7).

Mesfin et $\mathrm{al}^{4}$ reported on 34 patients treated with C3 laminectomy including modified C7 undercuts in patients who required it. C3 laminoplasty was avoided, with the belief that it contributes to postoperative axial pain. However, the present results demonstrating a low occurrence rate of postoperative axial pain associated with C3 lam- 


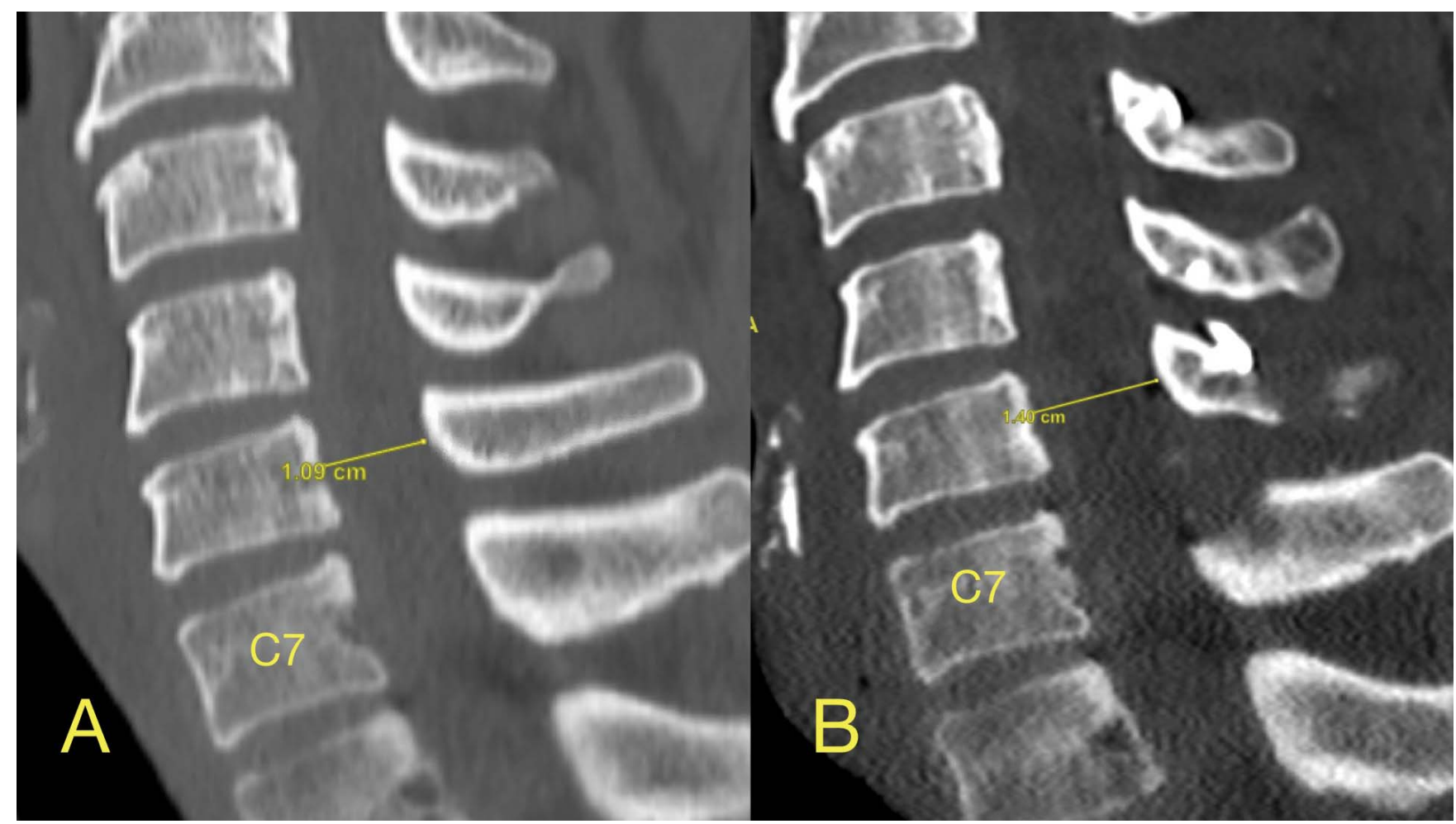

Figure 8. (A) Preoperative sagittal CT. At the C6 level the AP diameter of the osseous spinal canal is $10 \mathrm{~mm}$. (B) The dome laminotomy at C7 as well as the enlargement of the AP diameter of the osseous spinal canal to $14 \mathrm{~mm}$. This is a case relatively early in this case series. The amount of bony resection was relatively more extensive in patients operated on later in the series.

inoplasty suggest that the C3 laminectomy (used in their study) is possibly not necessary. The main criticism against C3 laminectomy is the disruption of the posterior tension band at the proximal end of the operated spine levels, which could theoretically contribute to delayed instability.

Sakaura et $\mathrm{al}^{9}$ reported long-term results following C3-C6 laminoplasty sparing muscles attached to the $\mathrm{C} 2$ and $\mathrm{C} 7$ spinous processes. They found that axial pain continued to decrease and neurologic function was preserved long-term, in general agreement with the results from our study. Sakaura et $\mathrm{al}^{10}$ reported zero occurrence of postoperative kyphotic deformity, consistent with the results in our study.

Lee et $\mathrm{al}^{5}$ found that at both 6-month and 1-year follow-up, patients who had been treated with C3 laminectomy experienced significantly lower mean pain than the patients treated with $\mathrm{C} 3$ laminoplasty. These results probably suggest the need for definitive decompression at $\mathrm{C} 2-\mathrm{C} 3$ vs $\mathrm{C} 3$ laminoplasty alone. We achieved definitive decompression through C2 undercut with C3-C6 laminoplasty. Our data that early and late axial pain decreased by $\sim 58 \%$ agree with the findings of Lee et $\mathrm{al}^{5}$ that mean postoperative axial pain scores decreased by
$55 \%-63 \%$ in the $\mathrm{C} 3$ laminectomy cohort. Given the similar outcomes, it appears preferable to maintain the integrity of the posterior tension band by performing a C3 laminoplasty with $\mathrm{C} 2$ undercut rather than $\mathrm{C} 3$ laminectomy.

Performing dome laminotomies does not require special equipment or any new skill set. The favorable results reported here include cases from the very beginning of the learning curve (Figure 8), suggesting no compromise on the safety or efficacy of the technique.

\section{CONCLUSIONS}

In summary, C3-C6 laminoplasty that includes $\mathrm{C} 2$ and $\mathrm{C} 7$ dome laminotomies was associated with satisfactory improvement in neurologic function (hand function, balance, urinary dysfunction) and long-term control of axial neck pain without significant early or late postoperative complications.

\section{REFERENCES}

1. Klineberg E. Cervical spondylotic myelopathy: a review of the evidence. Orthop Clin North Am. 2010;41(2):193-202.

2. Kimura I, Shingu H, Nasu Y. Long-term follow-up of 
cervical spondylotic myelopathy treated by canal-expansive laminoplasty. J Bone Joint Surg Br. 1995;77(6):956-961.

3. Riew KD, Raich AL, Dettori JR, Heller JG. Neck pain following cervical laminoplasty: does preservation of the $\mathrm{C} 2$ muscle attachments and/or C7 matter? Evid Based Spine Care J. 2013;4(1):42-53.

4. Mesfin A, Park MS, Piyaskulkaew C, et al. Neck pain following laminoplasty. Global Spine J. 2015;5(1):17-22.

5. Lee GW, Cho CW, Shin JH, Ahn MW. Which technique is better option for C3 segment in multilevel open-door laminoplasty of the cervical spine?: laminectomy versus laminoplasty. Spine (Phila Pa 1976). 2017;42(14):E833-E840.

6. Fujiyoshi T, Yamazaki M, Kawabe J, et al. A new concept for making decisions regarding the surgical approach for cervical ossification of the posterior longitudinal ligament: the K-line. Spine (Phila Pa 1976). 2008;33(26):E990-E993.

7. White AA III, Panjabi MM. Clinical Biomechanics of the Spine. 2nd ed. Baltimore, MD: Lippincott Williams \& Wilkins; 1990.

8. Hosono N, Sakaura H, Mukai Y, Fujii R, Yoshikawa H. C3-6 laminoplasty takes over C3-7 laminoplasty with significantly lower incidence of axial neck pain. Eur Spine $J$. 2006;15(9):1375-1379.

9. Sakaura H, Miwa T, Kuroda Y, Ohwada T. Incidence and risk factors for late neurologic deterioration after C3-C6 laminoplasty for cervical spondylotic myelopathy. Global Spine J. 2016;6(1):53-59.

10. Sakaura H, Hosono N, Mukai Y, Iwasaki M, Yoshikawa H. C3-6 laminoplasty for cervical spondylotic myelopathy maintains satisfactory long-term surgical outcomes. Global Spine J. 2014;4(3):169-174.

11. Lieberman EG, Radoslovich S, Marshall LM, Yoo JU.
Lower urinary tract symptoms and urinary bother are common in patients undergoing elective cervical spine surgery. Clin Orthop Relat Res. 2019;477(4):872-878.

12. Chang HJ, Lynm C, Glass RM. Urinary incontinence in older women. JAMA. 2010;303(21):2208. doi:10.1001/jama.303. 21.2208

Disclosures and COI: The authors report no multiplicity of interest that could affect the objectivity of the presented results. This research did not receive any specific grant from funding agencies in the public, commercial, or not-for-profit sectors. The study was approved by the institution's Investigational Review Board.

Corresponding Author: Konstantinos Margetis, Department of Neurosurgery, Mount Sinai Health System, 5 East 98th St, 7th Floor, New York, NY 10029. Phone: (212) 241-3649; Fax: (212) 410-0603; Email: konstantinos.margetis@ mountsinai.org.

Published 0 Month 2021

This manuscript is generously published free of charge by ISASS, the International Society for the Advancement of Spine Surgery. Copyright $\odot 2021$ ISASS. To see more or order reprints or permissions, see http://ijssurgery.com. 